De Riggi, Non-Suicidal Self-Injury in Our Schools: A Review and Research-Informed Guidelines for School Mental Health Professionals, 'Canadian Journal of School Psychology' (32, 2) pp. 122-143. Copyright @ 2016 . DOI: $10.1177 / 0829573516645563$.

\title{
Non-Suicidal Self-Injury in Our Schools: A Review and Research-Informed Guidelines for
}

\section{School Mental Health Professionals}

\section{Abstract}

Non-suicidal self-injury (NSSI), the immediate and deliberate destruction of one's own body tissue, without suicidal intent, and not for purposes that are socially accepted, is a critical concern for youth in schools. Despite significant scholarly advances and increasing clinical awareness of NSSI, many school mental health professionals (MHPs) continue to report feeling ill equipped to support students who self-injure, and emphasize a need for formal education about NSSI and its management in schools. Thus, the first part of this article summarizes current NSSI research on prevalence, age of onset, gender differences, functions, risk factors, and associations with suicide. Emerging from this review, the second part offers research-informed recommendations for MHPs managing NSSI in schools, including guidelines for (a) identifying students at elevated risk of selfinjury, (b) developing a protocol for school personnel's initial response to student selfinjury, (c) first-level assessment of NSSI, and (d) managing critical issues related to NSSI contagion and online activity.

\section{Keywords}

non-suicidal self-injury, adolescence, school mental health, mental health professionals

\section{Introduction}

Non-suicidal self-injury (NSSI) is the immediate and deliberate destruction of one's own body tissue, without suicidal intent, and not for purposes that are socially accepted (e.g., tattooing, body piercing; Nock \& Favazza, 2009). Adolescents and young adults who engage in NSSI most commonly report methods of scratching, cutting, 
De Riggi, Non-Suicidal Self-Injury in Our Schools: A Review and Research-Informed Guidelines for School Mental Health Professionals, 'Canadian Journal of School Psychology' (32, 2) pp. 122-143. Copyright @ 2016 . DOI: $10.1177 / 0829573516645563$.

bruising, head banging, and burning (Heath, Toste, Nedecheva, \& Charlebois, 2008;

Klonsky, 2007; Whitlock et al., 2011). This type of self-injury is distinct from selfinjurious behaviours (SIBs), such as stereotypic and repetitive behaviours seen among youth with developmental disabilities (American Psychiatric Association, 2013). It is also distinct from deliberate self-harm, a broader term that does not distinguish whether suicidal intent is present or not and includes indirect forms of self-harm such as substance use (Cooper et al., 2005). Consistent with many conceptualizations in the field, the current review focuses on NSSI that occurs in typically developing youth (Klonsky, Muehlenkamp, Lewis, \& Walsh, 2011; Nock \& Favazza, 2009).

The high prevalence of NSSI in non-clinical populations has contributed to the recent inclusion of NSSI as a distinct disorder warranting further research in Section 3 of the Diagnostic and Statistical Manual of Mental Disorders (5th ed.; DSM-5; American Psychiatric Association, 2013). This is of particular interest to mental health professionals (MHPs) in schools (i.e., school psychologists, counselors, social workers), as NSSI has also emerged as a significant issue in school settings (e.g., Muehlenkamp, Williams, Gutierrez, \& Claes, 2009; Toste \& Heath, 2010). With prevalence rates highest in adolescence and NSSI onset peaking during school-age years, MHPs in schools are at a unique vantage point for the identification and management of youth struggling with self-injury (e.g., Toste \& Heath, 2010). Indeed, in one recent study, nearly $70 \%$ of school MHPs reported having encountered at least one student who has engaged in NSSI (Berger, Hasking, \& Reupert, 2014). However, despite increasing clinical awareness and close contact with youth who self-injure, school MHPs also indicate a worrisome lack of training regarding NSSI and consistently report feeling "in the dark" and ill equipped to 
De Riggi, Non-Suicidal Self-Injury in Our Schools: A Review and Research-Informed Guidelines for School Mental Health Professionals, 'Canadian Journal of School Psychology' (32, 2) pp. 122-143. Copyright @ 2016. DOI:

$10.1177 / 0829573516645563$.

work effectively with students who self-injure (Berger et al., 2014; Berger, Reupert, \& Hasking, 2015b; Duggan, Heath, Toste, \& Ross, 2011; Heath, Toste, \& Beettam, 2006;

Heath, Toste, Sornberger, \& Wagner, 2011). In addition to feeling underprepared, researchers have found that school personnel (e.g., teachers) and MHPs may even hold misconceptions about NSSI, which may reinforce the student's belief that others (e.g., adults) do not under- stand them (Heath et al., 2011). Thus, school MHPs are in a unique position to identify and respond to this highly stigmatized behaviour among youth, and have a pivotal role in the prevention and timely treatment of NSSI within schools.

To date, only a limited number of articles provide reviews and recommendations for working with youth who self-injure in schools (e.g., Heath \& Lewis, 2013; Toste \& Heath, 2010). Often, these research reviews are not concise articles and do not con- sider implications for school MHPs. Moreover, existing reviews may not be entirely representative of current NSSI knowledge, as research on self-injury has doubled since 2006 (Web of Science, n.d.). In their review of the field, Lewis and Heath (2015)noted that research on NSSI over the past 5 years has resulted in many developments in our understanding of self-injury in youth that have direct implications for practice. Given how rapidly the field of NSSI is evolving, school MHPs may not have time or access to resources to familiarize themselves with current NSSI knowledge, and thus an overview of contemporary developments in the field is warranted. Accordingly, the present article offers a concise review of the latest research on NSSI, and relates these findings to recommendation for school practice to improve the identification of and initial response to youth who self-injure.

\section{Research Review}


De Riggi, Non-Suicidal Self-Injury in Our Schools: A Review and Research-Informed Guidelines for School Mental Health Professionals, 'Canadian Journal of School Psychology' (32, 2) pp. 122-143. Copyright @ 2016. DOI: $10.1177 / 0829573516645563$.

\section{Age of Onset and Prevalence}

NSSI onset tends to peak during early adolescence (11-15 years) and late adolescence (17-18 years; Klonsky \& Muehlenkamp, 2007; Muehlenkamp, Claes, Havertape, \& Plener, 2012; Rodham \& Hawton, 2009; Whitlock, Eckenrode, \& Silverman, 2006a). A major advancement in our knowledge of NSSI has been an increased understanding of the scope of self-injury in community samples (Andover, 2012). To this end, NSSI is emerging as more prevalent in the general population than previously believed (Muehlenkamp et al., 2012; Swannell, Martin, Page, Hasking, \& St John, 2014). Prevalence rates of NSSI are indeed the highest among adolescents, with $15 \%$ to $25 \%$ of teens reporting engagement in NSSI at least once in their lifetime (Jacobson \& Gould, 2007; Muehlenkamp \& Gutierrez, 2004; Nock \& Favazza, 2009), and $6 \%$ to $7 \%$ reporting self-injury at least once in the past year (Jacobson \& Gould, 2007). Studies also suggest that of all youth reporting any NSSI, nearly one quarter report that they engage in the behaviour repetitively (Berger, Hasking, \& Martin, 2013; Nixon \& Heath, 2009). Although researchers tend to agree that NSSI onset is most common in adolescence relative to preadolescence and young adulthood, prevalence rates are noted to fluctuate depending on the response format used, with open-ended questions and checklist methods resulting in lower and higher prevalence estimates, respectively (Heath, Toste, et al., 2008).

An important consideration especially relevant to school personnel and MHPs is that transition periods, such as the move from elementary to high school or from high school to university, represent vulnerable periods of heightened stress for youth (Taliaferro \& Muehlenkamp, 2015). During these transitions, school professionals should 
De Riggi, Non-Suicidal Self-Injury in Our Schools: A Review and Research-Informed Guidelines for School Mental Health Professionals, 'Canadian Journal of School Psychology' (32, 2) pp. 122-143. Copyright @ 2016 . DOI:

$10.1177 / 0829573516645563$.

be especially watchful of vulnerable youth at heightened risk of the use of unhealthy coping strategies such as self-injury to cope with stress.

\section{Gender Differences}

Even though researchers previously believed NSSI to be a predominantly female behaviour, current findings point to a more complex picture: Although most studies using adolescent samples have found females to report higher rates of NSSI compared with their male peers (e.g., Bakken \& Gunter, 2012; Bresin \& Schoenleber, 2015; Wilcox et al., 2012), approximately $8.5 \%$ of adolescent males engage in NSSI (Laye- Gindhu \& Schonert-Reichl, 2005; Nixon, Cloutier, \& Jansson, 2008). Moreover, the gender difference observed in adolescence appears to diminish by young adulthood, with comparable prevalence rates between young adult males and females (Heath, Toste, et al., 2008; Lewis \& Arbuthnott, 2012;Serras, Saules, Cranford, \& Eisenber, 2010;Whitlock, Eckenrode, \& Silverman, 2006). To date, it remains unclear whether the adolescent gender gap is reflective of actual gender differences in prevalence rates or a reluctance of male adolescents to report self-injury compared with their female adolescent peers (Bresin \& Schoenleber, 2015; Heath, Schaub, Holly, \& Nixon, 2008). For example, when asked open-ended questions about self-injury (e.g., "Do you hurt yourself on purpose without suicidal intent"), adolescents may assume this query to be limited to cutting, which is known to be more prevalent in females (e.g., Sornberger, Heath, Toste, \& McLouth, 2012). An additional consideration is the manner in which NSSI is defined and measured across various studies. Prior to the newly proposed DSM-5 diagnostic criteria for NSSI, definitions of self-injury have at times been broader and included behaviours such as risk taking (e.g., substance use; Laye-Gindhu \& Schonert-Reichl, 2005). Mixed 
De Riggi, Non-Suicidal Self-Injury in Our Schools: A Review and Research-Informed Guidelines for School Mental Health Professionals, 'Canadian Journal of School Psychology' (32, 2) pp. 122-143. Copyright @ 2016 . DOI:

$10.1177 / 0829573516645563$.

findings of NSSI behaviours among females and males may be reflective of these inconsistent definitions.

Although gender differences regarding the prevalence of NSSI remain unclear, firmer conclusions have been drawn regarding gender differences in the methods and location of self-injury. Specifically, research suggests that females are more likely to report cutting and scratching (Sornberger et al., 2012) and self-injuring their wrists or thighs (Whitlock et al., 2006a), whereas males are more likely to report self-injuring their hands, by punching or hitting themselves or an object (e.g., a wall) with the inten- tion of causing themselves harm. Thus, school MHPs should keep in mind that NSSI goes beyond "cutting" and that it also exists substantially among males (Sornberger et al., 2012). If school MHPs fail to recognize the variety of methods of NSSI being used (e.g., burning, punching), they may fail in identifying students who are engaging in NSSI. Thus, when screening for NSSI among students, it is recommended that school MHPs inquire about various methods of NSSI, for example, through the use of a checklist, for a more thorough assessment of the behaviours (Andover, Primack, Gibb, \& Pepper, 2010).

\section{Understanding Youth Who Self-Injure: NSSI Functions and Risk Factors}

\section{NSSI Functions}

Many youth who self-injure have difficulty explaining why they self-injure, and those who do often report multiple reasons for their self-injury that may change over time (Klonsky, 2007; Klonsky et al., 2011; Nock, 2009). Although NSSI is undoubtedly a multifaceted behaviour influenced by psychological, social, and biological factors, traditional empirically based models of NSSI function propose that the functions of selfinjury can be distilled into two primary functions rooted in behavioural reinforcement 
De Riggi, Non-Suicidal Self-Injury in Our Schools: A Review and Research-Informed Guidelines for School Mental Health Professionals, 'Canadian Journal of School Psychology' (32, 2) pp. 122-143. Copyright @ 2016 . DOI:

$10.1177 / 0829573516645563$.

principles, broadly characterized as the intrapersonal (e.g., affect regulation) and inter-

personal (e.g., help-seeking) functions of self-injury (Nock, 2009; Nock \& Prinstein, 2004, 2005). These are reviewed below.

Intrapersonal functions. The most commonly reported function of self-injury is the regulation of aversive affective experiences, whereby NSSI is used as a strategy to reduce, manage, or escape intense and intolerable negative emotions (e.g., sadness, anger, stress; Laye-Gindhu \& Schonert-Reichl, 2005; Rodham, Hawton, \& Evans, 2004). In these instances, self-injury serves to achieve an emotional/physiological "relief" (i.e., a lessening of unwanted negative feelings) for a short time (Klonsky, 2007, 2009; Nock \& Prinstein, 2004). For example, one study found that $52.9 \%$ of adolescents who selfinjured reported engaging in NSSI "to stop or release bad feelings" and "to relocate pain from emotional to physical" (Polk \& Liss, 2009). Individuals who self-injure also frequently report motivations related to self-hatred or self-directed anger, self-criticism, and self-punishment, reducing feelings of numbness or dissociation, to generate a feeling when feeling emotionally empty, and averting suicidal impulses or urges (Klonsky, 2007, 2009; Nock \& Prinstein, 2004).

Interpersonal functions. Although reported less often relative to intrapersonal functions of NSSI, individuals who self-injure also report engaging in NSSI for interpersonal reasons, such as using self-injury to communicate feelings of distress, or to attempt to deal with social problems (Klonsky, 2007; Nock, 2009; Nock \& Prinstein, 2004). Research suggests that engaging in NSSI for interpersonal reasons may reflect deeper difficulties with interpersonal problem solving (Klonsky, 2007, 2009; Nock \& Prinstein, 2004). For example, researchers have found that adolescents who engage in NSSI are more likely 
De Riggi, Non-Suicidal Self-Injury in Our Schools: A Review and Research-Informed Guidelines for School Mental Health Professionals, 'Canadian Journal of School Psychology' (32, 2) pp. 122-143. Copyright @ 2016. DOI:

$10.1177 / 0829573516645563$.

than their peers who do not engage in NSSI to have difficulty resolving interpersonal conflicts (Claes, Houben, Vandereycken, Bijttebier, \& Muehlenkamp, 2010; Nock \& Mendes, 2008), and report lower perceived social sup- port from family members and fewer individuals from whom to seek advice (Muehlenkamp, Brausch, Quigley, \& Whitlock, 2013). Furthermore, the reasons for engaging in self-injury are not static and may change over time, as some youth report social motivations for initiating NSSI (e.g., to communicate distress to others) and intrapersonally motivated reasons (e.g., emotion regulation) for maintaining or repeating the behaviours (Heath, Schaub, et al., 2008). This implies that school MHPs should be aware of the numerous functions of NSSI and understand how they may change over time.

It is important to note that although NSSI is frequently mistaken for an attentionseeking behaviour, research suggests that individuals seldom use self-injury to manipulate others or draw attention to themselves; indeed, most adolescents who selfinjure do so in private and do not tell others (Gratz, 2003). Experts in the NSSI field would argue that attention from others who are in a position to help is always warranted, as NSSI is a symptom of underlying distress and often an indication of more serious difficulties with coping (Toste \& Heath, 2010; Walsh, 2012; Whitlock \& Rodham, 2013).

\section{NSSI Risk Factors}

There is no single "cause" of NSSI, nor a single profile that can reliably predict who will self-injure. Nevertheless, understanding the common risk factors associated with self-injury may better equip school MHPs to understand common underlying difficulties for students at risk of self-injury.

In both community and clinical settings, research has consistently demonstrated 
De Riggi, Non-Suicidal Self-Injury in Our Schools: A Review and Research-Informed Guidelines for School Mental Health Professionals, 'Canadian Journal of School Psychology' (32, 2) pp. 122-143. Copyright @ 2016. DOI:

$10.1177 / 0829573516645563$.

that self-injury most often co-occurs in youth who struggle with emotion regulation difficulties (e.g., McKenzie \& Gross, 2014), which is also a core diagnostic criterion for various mental health difficulties (Sheppes, Suri, \& Gross, 2015). Many youth who engage in self-injury tend to also report higher rates of mental health difficulties relative to their non-self-injuring peers, including but not limited to higher rates of anxiety, depression, substance abuse, eating disorders, post-traumatic stress disorder, and suicide attempts (Hamza, Stewart, \& Willoughby, 2012; Hintikka et al., 2009; Jacobson, Muehlenkamp, Miller, \& Turner, 2008; Klonsky, May, \& Glenn, 2013; Stewart, Baiden, \& Theall-Honey, 2014; Whitlock et al., 2013). Importantly, however, even though NSSI has been associated with mental health difficulties, self-injury does not necessitate the presence of any particular psychological diagnosis (Klonsky et al., 2013; Nock, Joiner, Gordon, Lloyd-Richardson, \& Prinstein, 2006), and oftentimes, these diagnoses are not appropriate for the majority of youth who engage in NSSI (e.g., Andover, Pepper, Ryabchenko, Orrico, \& Gibb, 2005; Walsh, 2012). As such, it is important for school MHPs to keep in mind that although mental health difficulties commonly co-occur among youth who engage in NSSI, self-injury is not an inevitable symptom of an underlying mental disorder.

An additional risk factor for self-injury is interpersonal difficulties. Specifically, it is theorized that individuals who engage in NSSI habituate themselves to turning difficult emotions inward rather than communicating their difficulties outward, and use selfinjury as a tool to manage emotional pain resulting from interpersonal problems (e.g., Muehlenkamp et al., 2013; Nock, 2010). Supporting this notion, youth who self-injure commonly report poor interpersonal coping skills, such as deficits in social problem 
De Riggi, Non-Suicidal Self-Injury in Our Schools: A Review and Research-Informed Guidelines for School Mental Health Professionals, 'Canadian Journal of School Psychology' (32, 2) pp. 122-143. Copyright @ 2016 . DOI: $10.1177 / 0829573516645563$.

solving and communication (e.g., Andrews, Martin, Hasking, \& Page, 2014; Nock \& Mendes, 2008). The family context is an additional interpersonal risk factor for selfinjury. Although many youth who engage in NSSI report that they come from loving and caring families, many also report frequent difficulties communicating their emotions with their parents (Crowell et al., 2013). Furthermore, frequent parental criticism/ invalidation of the child may lead to a sense of self-criticism and personal invalidation for the youth (Andrews et al., 2014). Recent evidence supports that adolescents who self-injure often report high levels of self-criticism and self-dissatisfaction (e.g., Victor \& Klonsky, 2014b), lower levels of self-esteem (e.g., Lundh, Karim, \& Quilisch, 2007), and an increased sense of hopelessness (e.g., Fox et al., 2015) and ineffectiveness and body dissatisfaction compared with their peers (e.g., Ross, Heath, \& Toste, 2009).

Overall, MHPs working with youth who self-injure should be aware of the intrapersonal difficulties (e.g., difficulties with emotion regulation), mental health difficulties (e.g., anxiety, depression), and/or interpersonal risk factors (e.g., poor interpersonal 
De Riggi, Non-Suicidal Self-Injury in Our Schools: A Review and Research-Informed Guidelines for School Mental Health Professionals, 'Canadian Journal of School Psychology' (32, 2) pp. 122-143. Copyright @ 2016 . DOI:

$10.1177 / 0829573516645563$.

coping skills, parental criticism, self-criticism) may be associated with NSSI among youth. An understanding of the underlying difficulties that are commonly associated with NSSI among youth is important for school MHPs to have a broader understanding of students at risk of self-injury.

\section{The Link Between NSSI and Suicide}

The association between NSSI and suicidal behaviours is frequently

misunderstood. A common misconception is that NSSI and suicidal behaviours (e.g., suicide attempt) are identical as they share surface-level similarity in that they both imply self-inflicted harm (Klonsky et al., 2013). However, it is well established that NSSI is distinct from suicidal behaviours and it is thus critical that NSSI and suicide be understood, managed, and treated in their own respective manners (Walsh, 2012). For example, whereas the intent of suicidal actions is to end one's life, NSSI, by definition, is without intent to die, and may even be used as an attempt to avoid suicidal urges (e.g., Klonsky, 2007; Klonsky \& Muehlenkamp, 2007). NSSI and suicidal behaviours are also typically distinguished by their severity: Whereas suicide is highly lethal and requires medical attention, NSSI has low lethality and rarely requires medical attention (Muehlenkamp, 2005; Nock \& Favazza, 2009). Suicide is also less prevalent and less frequent than NSSI (Walsh, 2012). Despite these differences, an important consideration for all school MHPs is that although NSSI and suicide are distinct behaviours, they are not mutually exclusive. The link between NSSI and suicidality is nuanced and has gained increasing empirical and clinical interest in the past several years (Klonsky et al., 2013; Nock, 2012; Victor \& Klonsky, 2014a; Whitlock et al., 2013). This surge of research has 
De Riggi, Non-Suicidal Self-Injury in Our Schools: A Review and Research-Informed Guidelines for School Mental Health Professionals, 'Canadian Journal of School Psychology' (32, 2) pp. 122-143. Copyright @ 2016 . DOI:

$10.1177 / 0829573516645563$.

highlighted a more complex understanding of NSSI as a unique risk factor for suicidal behaviour (Klonsky et al., 2013). More specifically, one study found that in a community sample of adolescents, those who engaged in NSSI were seven times more likely to attempt suicide in the future, even when depressive symptoms were controlled (Guan, Fox, \& Prinstein, 2012). Factors that further increase the risk of suicide include engaging in NSSI more frequently, for prolonged periods of time, use of multiple methods, and NSSI escala- tion and/or feeling no pain during NSSI (Heath \& Nixon, 2009; Klonsky et al., 2013; Nock, 2009). As such, when a student is referred for self-injury, must be adequately equipped to assess for both self-injury and suicidal behaviours (Heath \& Nixon, 2009; Klonsky et al., 2011) and suicide risk assessment should be part of both the initial evaluation and ongoing treatment.

In summary, current research suggests that school MHPs should be aware of adolescents' potential use of NSSI as an unhealthy coping strategy, especially during periods of heightened stress. Furthermore, the current review highlights the importance of understanding gender differences in the various methods of self-injury, the various intrapersonal and interpersonal functions of NSSI, and the risk that NSSI poses for a future suicide attempt. In light of these findings and drawing on current clinical recommendations in the field (e.g., Klonsky \& Lewis, 2014; Klonsky et al., 2011; Walsh, 2012), specific recommendations for MHPs for the identification and management of NSSI in schools are offered below.

\section{Recommendations for School MHPs}

\section{Identifying Youth Who Self-Injure}

Identifying youth who self-injure may be challenging, as youth who engage in 
De Riggi, Non-Suicidal Self-Injury in Our Schools: A Review and Research-Informed Guidelines for School Mental Health Professionals, 'Canadian Journal of School Psychology' (32, 2) pp. 122-143. Copyright @ 2016 . DOI:

$10.1177 / 0829573516645563$.

NSSI are often secretive about their self-injury. In addition, parental awareness rates are considerably lower than youth NSSI rates (Arbuthnott \& Lewis, 2015; Baetens et al., 2014), and only a small proportion of youth who self-injure seek help from MHPs (Rowe et al., 2014). Rather, research indicates that it is more common among youth who engage in NSSI to disclose their NSSI to a close friend or peer (e.g., Berger et al., 2013; Muehlenkamp, Walsh, \& McDade, 2010), and this disclosure is often experienced as discomforting for the student's peers who report feeling unsure of how to respond (Berger et al., 2013). When a student's self-injury is identified by school personnel through the disclosure of a peer, it is imperative that the disclosing peer also receive support and be reassured that the disclosure is a positive step in getting the identified student the support he or she needs.

When aware of the risk factors and warning signs for NSSI, school personnel and MHPs may also serve as important identifiers of youth struggling with self- injury. As reviewed above, research points to several factors associated with higher risk of NSSI, such as difficulties with emotion regulation, interpersonal problems, and suicide (for a review, see Lewis \& Heath, 2015). In addition, school personnel should pay attention to overt warning signs that may be concerning (e.g., unexplained cuts, bruises, burns, scratches or scars), and other indicators of possible self-injury such as wearing clothing that is inappropriate for the weather (e.g., long sleeves in heat), a reluctance to take part in activities requiring a change of clothes (e.g., gym, swimming), frequent use of bandages or wrist coverings, expression of self-injurious ideas (e.g., in classwork, personal writing, or conversations), and frequent need for privacy or secretive behaviour (Heath \& Nixon, 2009; Walsh, 2012). 
De Riggi, Non-Suicidal Self-Injury in Our Schools: A Review and Research-Informed Guidelines for School Mental Health Professionals, 'Canadian Journal of School Psychology' (32, 2) pp. 122-143. Copyright @ 2016 . DOI:

$10.1177 / 0829573516645563$.

The indicators outlined should elicit further inquiry rather than an immediate assumption of self-injury. Furthermore, the need to probe an array of possible methods of NSSI beyond cutting (e.g., burning, self-hitting) is important. However, as noted above, the majority of students who engage in NSSI may not come to the notice of school psychologists and thus an understanding of the factors and mental health difficulties that co-occur with NSSI (e.g., emotion dysregulation, self-criticism) not only equips the school MHP to better identify students at increased risk for self-injury, but also facilitates detailed assessment and effective treatment for youth already identified as engaging in NSSI. In addition, universal programs that address difficulties in cop- ing with emotion regulation and self-criticism should be offered.

\section{Initial Response}

When youth disclose their self-injury or are confronted about suspected selfinjury, the approach of the initial responder may play a critical role in the youth's future help seeking, willingness to discuss his or her NSSI, and accepting of support (Heath, Baxter, Toste, \& McLouth, 2010). Researchers have found that it is common for school personnel and MHPs to experience strong reactions themselves when first encountering a youth engaging in NSSI, such as discomfort, anger, frustration, sad- ness, helplessness, and even repulsion (Alderman, 2000; Heath et al., 2011; White Kress, Gibson, \& Reynolds, 2004). Professionals working with these youth are strongly advised to monitor these reactions and be aware of their impact on the youth, so as to not over- or underreact to a student's NSSI. Those who engage in NSSI are likely to have already faced harsh judgments and stigma about their self- injury, and strong emotional reactions from initial responders are likely to make the students feel embarrassed or shameful, increase their 
De Riggi, Non-Suicidal Self-Injury in Our Schools: A Review and Research-Informed Guidelines for School Mental Health Professionals, 'Canadian Journal of School Psychology' (32, 2) pp. 122-143. Copyright @ 2016 . DOI:

$10.1177 / 0829573516645563$.

sense of alienation and dis- trust, and make them even less likely to communicate about the behaviour in the future (Toste \& Heath, 2010). Moreover, strong reactions to the disclosing youth may increase their distress and inadvertently reinforce their self-injury, making it more likely to occur in the future (Toste \& Heath, 2010). Instead, experts working with those who engage in NSSI advise a calm, caring, and compassionate demeanor when discussing self-injury, so as to give the youth a sense of relief and comfort (Klonsky \& Lewis, 2014; Klonsky et al., 2011; Walsh, 2012). Other guidelines include avoiding the immediate labeling of NSSI as a suicidal behaviour prior to appropriate suicide risk assessment, using the student's own descriptive language (e.g., some students may refer to their self-injury as "cutting," "burning," etc.) when discussing NSSI, and maintaining an active listening stance that refrains from advice giving or story telling about others who self-injure (Klonsky \& Lewis, 2014; Walsh, 2012).

\section{Developing a School Protocol}

Effective identification of and response to NSSI necessitates a school-wide system- atic approach. Toward this end, a number of authors have urged that protocols for responding to NSSI be implemented in schools as an explicit agreement among school personnel about how incidents or reports of NSSI will be managed (e.g., Berger, Hasking, \&Reupert, 2015a; Walsh \& Muehlenkamp, 2013). Key issues to be addressed in school protocols include (a) when school personnel (i.e., teachers, para- professionals, etc.) must report a student suspected of self-injuring (e.g., after observation of warning signs, peer disclosure, or self-disclosure), (b) to whom this should be reported (i.e., the designated school MHP), (c) a clarification of the roles of each person (i.e., the reporting school personnel, the designated MHP, the school principal, etc.) involved in the 
De Riggi, Non-Suicidal Self-Injury in Our Schools: A Review and Research-Informed Guidelines for School Mental Health Professionals, 'Canadian Journal of School Psychology' $(32,2)$ pp. 122-143. Copyright @ 2016. DOI:

$10.1177 / 0829573516645563$.

management of the student who is engaging in NSSI, and (d) policies to guide the suicide risk assessment by the designated MHP. For example, many authors suggest that the sole role of reporting school personnel should be the referral of the youth to a designated MHP (not to discuss the youths self-injury in detail, assess suicide risk, or contact parents), and that the designated MHP should have his or her own guidelines for when parental notification and referral to outside services is warranted (Bubrick, Goodman, \& Whitlock, 2010). Furthermore, all school protocols should have an identified replacement for the designated MHP in the event of absence. Finally, it is imperative that school personnel and MHPs observe their own level of comfort in working with students who engage in NSSI, and an immediate referral to an identified colleague should be arranged in the event that an individual does not feel fully informed or prepared to support students who engage in self-injury (Toste \& Heath, 2010). Notably, simply having an NSSI protocol does not guarantee that the protocol will be implemented in schools (Berger et al., 2015a). Research suggests that additional teacher training on NSSI knowledge, including how to use the protocol, along with widespread support from key stakeholders within the education system will help ensure that school staff respond to NSSI consistently (Berger et al., 2015a).

\section{Screening and Risk Assessment}

It is most likely that the designated school MHP becomes aware of a student's self- injury through his or her own observation of the student, by the disclosure of the student himself or herself, or through concerns voiced by peers, teachers, or parents (White Kress et al., 2004). Regardless of how self-injury is discovered, any student who is believed to be engaging in self-injury must be screened and assessed for both self- 
De Riggi, Non-Suicidal Self-Injury in Our Schools: A Review and Research-Informed Guidelines for School Mental Health Professionals, 'Canadian Journal of School Psychology' (32, 2) pp. 122-143. Copyright @ 2016 . DOI:

$10.1177 / 0829573516645563$.

injury and suicide as part of both the initial evaluation and ongoing monitoring of the youth (Heath \& Nixon, 2009). In their recent review of NSSI among youth for physicians, Lewis and Heath (2015) recommend posing a series of questions that are also applicable to MHPs addressing NSSI in schools. During initial screening of a student that may be engaging in self-injury, the school MHP should first inquire about the youth's general stress (e.g., overall, how stressed has the youth been feeling over the past few weeks?), and follow up with questions about their mood and demeanor during this period (i.e., depressive symptoms, anxiety symptoms, etc.). After this initial questioning, the MHP may suggest that sometimes students who are struggling with stress, depression, or anxiety engage in certain strategies to cope with their feelings, some of which may include self-harming behaviours such as substance misuse or self-injury. It is then recommended that the MHP directly inquire about whether the student has ever used any of these strategies to cope with the stress or emotions himself or herself (Lewis \& Heath, 2015). Generally, clinicians have found this approach to facilitate the identification of NSSI without drawing excessive attention to the behaviour (Nixon \& Heath, 2009; Taliaferro et al., 2013).

Should initial screening reveal that a student is engaging or has engaged in NSSI, the student must be formally assessed for NSSI and suicide so as to guide appropriate referral based on the youth's determined level of risk. A central component of this assessment is determining risk for suicide. Minimally, suicide risk assessment involves questioning the student's history of suicide attempts, current thoughts about suicide, intensity and frequency of suicidal ideation, suicidal intent (i.e., a desire to die), and suicide plan (Simon \& Hales, 2012). For youth who engage in NSSI, multiple methods 
De Riggi, Non-Suicidal Self-Injury in Our Schools: A Review and Research-Informed Guidelines for School Mental Health Professionals, 'Canadian Journal of School Psychology' $(32,2)$ pp. 122-143. Copyright @ 2016. DOI:

$10.1177 / 0829573516645563$.

and/or locations of injuries, a longer history of NSSI, and/or recent worsening (e.g., increased frequency and/or severity), and co- occurring substance use are known to be associated with increased risk for suicide (Klonsky, 2007). In addition, a youth's perception that he or she is "addicted to the self- injury" is associated with more a severe profile of NSSI (Barrocas, Hankin, Young, \& Abela, 2012).

Although the severity of the youth's injury may be of concern, researchers suggest that it is inappropriate to ask to see the injuries, as revealing them may be experienced as highly aversive for the youth (Nixon \& Heath, 2009). Alternatively, asking the youth if medical attention has been required for their injuries offers a less invasive indication of severity (Lewis \& Heath, 2015). A final component of risk assessment is inquiring about whether or not anyone else (e.g., other professionals, friends, family members, adults, online communities) is aware of the youth's self-injury. This information allows for a more complete understanding of the student's support system and assists in future monitoring and intervention.

In the event that a student is considered an immediate high risk (i.e., a suicide risk or requiring medical attention for the injuries), the student should be immediately referred to emergency mental health services (Lewis \& Heath, 2015; Walsh \& Muehlenkamp, 2013). If the MHP identifies factors other than suicide and required medical assistance, then it is recommended that the student receive prompt follow-up and ongoing monitoring to keep track of possible changes in the student's profile that may place him or her at higher risk (Lewis \& Heath, 2015).

Assessment tools. To guide the identification of NSSI thoughts and behaviours, it is recommended to use one of the available empirically validated self-report measures 
De Riggi, Non-Suicidal Self-Injury in Our Schools: A Review and Research-Informed Guidelines for School Mental Health Professionals, 'Canadian Journal of School Psychology' (32, 2) pp. 122-143. Copyright @ 2016 . DOI:

$10.1177 / 0829573516645563$.

(e.g., the Inventory of Statements About Self-Injury [ISAS; Klonsky \& Glenn, 2009], the Ottawa Self-Injury Inventory [OSI; Nixon, Levesque, Preyde, Vanderkooy, \& Cloutier, 2015], the Non-Suicidal Self-Injury-Assessment Tool [NSSI-AT; Whit- lock, ExnerCortens, \& Purington, 2014]) or interviews (e.g., Self-Injurious Thoughts and Behaviors Interview [SITBI; Nock, Holmberg, Photos, \& Michel, 2007], Suicide Attempt SelfInjury Interview [SASII; Linehan, Comtois, Brown, Heard, \& Wagner, 2006]). Klonsky and Lewis (2014) provide a review of the assess- ment focus and psychometric properties of each assessment tool (Klonsky \& Lewis, 2014). Importantly, though these tools may aid in guiding risk assessment and poten- tial harm, they should not be used to predict future suicide or risk of life-threatening self-harm in and of themselves (LloydRichardson, Lewis, Whitlock, Rodham, \& Schatten, 2015).

\section{Parental Notification}

Parental notification of a youth's self-injury remains a controversial issue among school-based professionals. School MHPs must often weigh legal responsibilities (i.e., to schools and to parents) with ethical decisions when dealing with students who engage in NSSI. Once a student has disclosed his or her NSSI, breach of confidentiality can mean further harm for an already alienated student (White Kress, Drouhard, \& Costin, 2006). Thus, the school MHP is in a unique and challenging position to consider at what point parents and school administrators have the right to student confidential information. Although each school board or individual school may have a different policy regarding parental notification, it is critical that the policy is agreed on and clearly stated at the local level and included in the school protocol (Toste \& Heath, 2010). It has been suggested that if a youth is determined low risk for suicide and does not present with serious mental health 
De Riggi, Non-Suicidal Self-Injury in Our Schools: A Review and Research-Informed Guidelines for School Mental Health Professionals, 'Canadian Journal of School Psychology' (32, 2) pp. 122-143. Copyright @ 2016 . DOI:

$10.1177 / 0829573516645563$.

concerns, then NSSI, like other high-risk behaviours (e.g., drug use) may not require parental contact (Lieberman, Toste, \& Heath, 2009; Nixon \& Heath, 2009). Importantly however, this does not suggest that the student is not in significant distress, and he or she should still receive therapeutic support and follow-up assessments to ensure that his or her risk level has not changed. If the adolescent is believed to be at serious risk to himself or herself, the school MHP is advised to contact the student's parents (Toste \& Heath, 2010), and it is strongly recommended that the student be advised in advance that his or her parents will be notified, and that he or she is present and involved in the process during the phone call so that they are aware of the specifics of the communication (Bubrick et al., 2010; Nixon \& Heath, 2009). Important next steps include a discussion of how to provide a supportive and appropriate environ- ment for the student during this difficult time. Specifically, helping parents under- stand the difference between helpful and unhelpful responses to self-injury and related issues is critical to ensure a positive and supportive parent-child dynamic (Arbuthnott \& Lewis, 2015; Walsh, 2012).

Likewise, this is often a difficult situation for the parents and it is recommended that the parents be provided with basic information and resources about NSSI to help them understand their son or daughter's behaviour prior to discussion with the child (Arbuthnott \& Lewis, 2015; Toste \& Heath, 2010).

\section{NSSI and Social Contagion}

Social contagion of NSSI refers to the presence of NSSI in at least two people in the same group in a 24-hr time period (Rosen \& Walsh, 1989) or statistically significant clusters of NSSI in the same group (Walsh \& Rosen, 1985). Social contagion of NSSI has been observed among community samples of adolescents (e.g., Nock, Prinstein, \& 
De Riggi, Non-Suicidal Self-Injury in Our Schools: A Review and Research-Informed Guidelines for School Mental Health Professionals, 'Canadian Journal of School Psychology' (32, 2) pp. 122-143. Copyright @ 2016 . DOI:

$10.1177 / 0829573516645563$.

Sterba, 2009) and among students (Muehlenkamp, Hoff, Licht, Azure, \& Hasenzahl, 2008; Ross et al., 2009), and thus represents a major concern for school MHPs working with youth who self-injure. Although it was previously believed that limiting discussion of NSSI was appropriate, research is finding that youth are nevertheless exposed to NSSI often through their peers or media influences (e.g., Jarvi, Jackson, Swenson, \& Crawford, 2013), and unfortunately, very few youth seek help directly from an adult or school MHPs (e.g., Heath, Toste, et al., 2008). The following guide- lines are thus recommended to manage and minimize the risk of social contagion of NSSI.

Researchers suggest that fostering students' perceptions of school MHPs as a non- judgmental source of support and alleviating student concerns regarding breaches of confidentiality and stigma associated with help seeking are effective ways to reduce self-injury and its contagion (Fortune, Sinclair, \& Hawton, 2008). Thus, a primary recommendation for school MHPs is to make their availability and support known to youth, and to encourage students to speak with the school MHP when they are experiencing any distress (not limited to NSSI). Second, it is recommended that school MHPs carefully provide accurate information and resources about self-injury to all students within the broader context of unhealthy coping strategies (Jarvi et al., 2013; Toste \& Heath, 2010). Although this may be uncomfortable or frightening for a student who is engaging in NSSI, demonstrating awareness that NSSI is a fairly common unhealthy coping strategy can normalize help seeking and make it seem less intimidating (Toste \& Heath, 2010).

Importantly, though it is imperative for school personnel to be mindful of the particular signs and symptoms of NSSI (e.g., prevalence, methods of self-injury), this level of detail is not appropriate for students. Rather, students may be educated on how to recognize general 
De Riggi, Non-Suicidal Self-Injury in Our Schools: A Review and Research-Informed Guidelines for School Mental Health Professionals, 'Canadian Journal of School Psychology' (32, 2) pp. 122-143. Copyright @ 2016. DOI:

$10.1177 / 0829573516645563$.

signs of distress and emotional health difficulties (e.g., feeling depressed, anxious, or overly strained) and taught the use of healthy coping skills and stress management (Toste \& Heath, 2010; Whitlock \& Rodham, 2013). Furthermore, school personnel should be aware that some materials and discussion topics may trigger SIBs and students should never be provided explicit or detailed information regarding NSSI or be shown images and videos (Toste \& Heath, 2010).

\section{NSSI Online}

Recently within the field, online NSSI activity has been recognized by researchers and NSSI-based organizations (e.g., International Society for the Study of Self-Injury) as a new and primary area of concern (e.g., Lewis, Heath, Michal, \& Duggan, 2012a; Mahdy \& Lewis, 2013). The recent surge of research around NSSI online activity highlights that, in fact, many youth use the Internet as a means to obtain information and resources (Lewis, Mahdy, Michal, \& Arbuthnott, 2014; Lewis, Rosenrot, \& Messner, 2012), to post NSSI material and images (Lewis \& Baker, 2011), and to communicate about their experiences online through e-platforms and/or e-communities on social networking websites such as Facebook, Instagram, and YouTube (for a review, see Lewis $\&$ Seko, 2016). Indeed, a number of studies have indicated that many youth who engage in NSSI and who may otherwise be isolated use the Internet as a form of social support by communicating and connecting with others (e.g., Lewis, Heath, Sornberger, \& Arbuthnott, 2012b; Lewis et al., 2014; Lewis et al., 2012c; Rodham, Gavin, Lewis, St. Denis, \& Bandalli, 2013). NSSI e-communities also provide resources (e.g., coping tips) and may present encouraging, recovery-focused messages (Lewis \& Michal, 2016; Lewis, Heath, St. Denis, \& Noble, 2011). Despite the mentioned benefits associated with 
De Riggi, Non-Suicidal Self-Injury in Our Schools: A Review and Research-Informed Guidelines for School Mental Health Professionals, 'Canadian Journal of School Psychology' (32, 2) pp. 122-143. Copyright @ 2016 . DOI:

$10.1177 / 0829573516645563$.

online activities, there are also potential risks, particularly among peer-driven websites (Duggan, Heath, Lewis, \& Baxter, 2012; Lewis et al., 2012a). Of particular concern is research indicating that exposure to certain messages about NSSI, including hopeless messages concerning NSSI recovery and justifying NSSI as a means to manage distress, may normalize and reinforce NSSI. In other words, repeated access to these types of messages may impede help-seeking or recovery-oriented efforts and thus maintain NSSI continuation (e.g.,Lewis et al., 2012a; Lewis et al., 2012b). In addition to this, viewing explicit images of self-harm may have a triggering effect, leading to heightened NSSI urges (e.g., Lewis \& Baker, 2011; Lewis \& Knoll, 2015; Lewis et al., 2011). NSSI online activity may also expose youth to strategies that contribute to NSSI maintenance, including new ways to self- injure, first-aid tips, and methods of concealing NSSI from others (Lewis \& Baker, 2011; Lewis \& Knoll, 2015; Lewis et al., 2011; Rodham et al., 2013; Whitlock, Powers, \& Eckenrode, 2006b). Therefore, it is important for school MHPs who work with youth who engage in NSSI to consider online activity in assessment and treatment contexts, as helping youth substitute healthier online activities may be more effective in facilitating recovery than attempting to eliminate online activities altogether (e.g., Lewis, Heath, Michal, \& Duggan, 2012). Likewise, it is important that school MHPs recognize many online NSSI activities may have benefits, including mitigation of social isolation, curbing NSSI urges, and recovery encouragement (for a review, see Lewis \& Seko, 2015). Finally, is also recommended that that school MHPs familiarize and educate themselves with online NSSI activity. Specifically, it is suggested that school MHPs (a) become familiar with professionally driven websites, such as $\mathrm{SiOS}$ (http://sioutreach.org) and S.A.F.E (http://www.selfinjury.com), and peer- 
De Riggi, Non-Suicidal Self-Injury in Our Schools: A Review and Research-Informed Guidelines for School Mental Health Professionals, 'Canadian Journal of School Psychology' (32, 2) pp. 122-143. Copyright @ 2016. DOI: $10.1177 / 0829573516645563$.

driven websites, such as Psyke (http://www.psyke.org); (b) note moderator sta- tus, presence of triggering material, and pro- versus anti-NSSI themes across websites;

(c) note content differences in character and non-character videos concerning NSSI; and (d) become familiar with themes among online support groups, which may range from educational and supportive to normalizing and reinforcing (Duggan et al., 2011; Mahdy \& Lewis, 2013). By conducting brief Internet searches to survey various web- site types, school MHPs will gain hands-on experience concerning the NSSI online youth perspective. A list of recommended NSSI online and offline resources is pro- vided in Appendix table A1.

\section{Summary}

Whereas approximately $15 \%$ to $25 \%$ of youth report having engaged in NSSI (e.g., Whitlock et al., 2006a), over 70\% of school MHPs indicate that they are ill equipped to serve these students and that they need more training in this area (Berger et al., 2014; Duggan et al., 2011). Given the mental health difficulties (e.g., anxiety, depression, suicide) associated with NSSI, along with the stigma and lack of help seeking among adolescents who self-injure (Toste \& Heath, 2010), it is imperative that school MHPs receive current information needed to effectively identify, respond to, and support students who engage in self-injury. With this information, school MHPs have recent NSSI knowledge and are better prepared to identify NSSI, conduct first-level assessments, and create a school-wise response to NSSI to best support students who selfinjure. 
De Riggi, Non-Suicidal Self-Injury in Our Schools: A Review and Research-Informed Guidelines for School Mental Health Professionals, 'Canadian Journal of School Psychology' (32, 2) pp. 122-143. Copyright @ 2016 . DOI:

\section{References}

Alderman, T. (2000). Helping those who hurt themselves. The Prevention Researcher, 7(4), 5-8. American Psychiatric Association. (2013). Diagnostic and statistical manual of mental disorders (5th ed.). Arlington, VA: American Psychiatric Publishing.

Andover, M. S. (2012). Advances in conceptualization and treatment of nonsuicidal self-injury (NSSI): Introduction to the special issue. Journal of Cognitive Psychotherapy, 26, 283286. Andover, M. S., Pepper, C. M., Ryabchenko, K. A., Orrico, E. G., \& Gibb, B. E. (2005). Self- mutilation and symptoms of depression, anxiety, and borderline personality disorder.Suicide and Life-Threatening Behavior, 35, 581-591.

Andover, M. S., Primack, J. M., Gibb, B. E., \& Pepper, C. M. (2010). An examination of nonsuicidal self-injury in men: Do men differ from women in basic NSSI characteristics? Archives of Suicide Research, 14, 79-88.

Andrews, T., Martin, G., Hasking, P., \& Page, A. (2014). Predictors of onset for non-suicidal self-injury within a school-based sample of adolescents. Prevention Science, 15, 850-859. Arbuthnott, A. E., \& Lewis, S. P. (2015). Parents of youth who self-injure: A review of the lit- erature and implications for mental health professionals. Child and Adolescent Psychiatry and Mental Health, 9, Article 35.

Baetens, I., Claes, L., Onghena, P., Grietens, H., Van Leeuwen, K., Pieters, C., \& Griffith, J. W. (2014). Non-suicidal self-injury in adolescence: A longitudinal study of the relationship between NSSI, psychological distress and perceived parenting. Journal of Adolescence, 
De Riggi, Non-Suicidal Self-Injury in Our Schools: A Review and Research-Informed Guidelines for School Mental Health Professionals, 'Canadian Journal of School Psychology' (32, 2) pp. 122-143. Copyright @ 2016 . DOI:

$10.1177 / 0829573516645563$.

$37,817-826$.

Bakken, N. W., \& Gunter, W. D. (2012). Self-cutting and suicidal ideation among adolescents:

Gender differences in the causes and correlates of self-injury. Deviant Behavior, 33, 339356.

Barrocas, A. L., Hankin, B. L., Young, J. F., \& Abela, J. R. (2012). Rates of nonsuicidal selfinjury in youth: Age, sex, and behavioral methods in a community sample. Pediatrics, $130,39-45$.

Berger, E., Hasking, P., \& Martin, G. (2013). “Listen to them”: Adolescents' views on helping young people who self-injure. Journal of Adolescence, 36, 935-945.

Berger, E., Hasking, P., \& Reupert, A. (2014). "We're working in the dark here": Education needs of teachers and school staff regarding student self-injury. School Mental Health, 6, 201-212.

Berger, E., Hasking, P., \& Reupert, A. (2015a). Developing a policy to address nonsuicidal selfinjury in schools. Journal of School Health, 85, 629-647.

Berger, E., Reupert, A., \& Hasking, P. (2015b). Pre-service and in-service teachers' knowledge, attitudes and confidence towards self-injury among pupils. Journal of Education for Teaching, 41, 37-51.

Bresin, K., \& Schoenleber, M. (2015). Gender differences in the prevalence of nonsuicidal selfinjury: A meta-analysis. Clinical Psychology Review, 38, 55-64.

Bubrick, K., Goodman, J., \& Whitlock, J. (2010). Non-suicidal self-injury in schools: Developing and implementing school protocol [Fact sheet] (Cornell Research Program on Self-Injurious Behavior in Adolescents and Young Adults). Retrieved from http://www. selfinjury.bctr.cornell.edu/documents/schools.pdf 
De Riggi, Non-Suicidal Self-Injury in Our Schools: A Review and Research-Informed Guidelines for School Mental Health Professionals, 'Canadian Journal of School Psychology' (32, 2) pp. 122-143. Copyright @ 2016. DOI: $10.1177 / 0829573516645563$.

Claes, L., Houben, A., Vandereycken, W., Bijttebier, P., \& Muehlenkamp, J. (2010). Brief report: The association between non-suicidal self-injury, self-concept and acquaintance with self-injurious peers in a sample of adolescents. Journal of Adolescence, 33, 775-778. Cooper, J., Kapur, N., Webb, R., Lawlor, M., Guthrie, E., Mackway-Jones, K., \& Appleby,

L. (2005). Suicide after deliberate self-harm: A 4-year cohort study. American Journal of Psychiatry, 162, 297-303.

Crowell, S. E., Baucom, B. R., McCauley, E., Potapova, N. V., Fitelson, M., Barth, H., .. . Beauchaine, T. P. (2013). Mechanisms of contextual risk for adolescent self-injury: Invalidation and conflict escalation in mother-child interactions. Journal of Clinical Child \& Adolescent Psychology, 42, 467-480.

Duggan, J. M., Heath, N. L., Lewis, S. P., \& Baxter, A. L. (2012). An examination of the scope and nature of non-suicidal self-injury online activities: Implications for school men- tal health professionals. School Mental Health, 4, 56-67.

Duggan, J. M., Heath, N. L., Toste, J. R., \& Ross, S. (2011). School counsellors' understanding of non-suicidal self-injury: Experiences and international variability. Canadian Journal of Counselling and Psychotherapy/Revue canadienne de counseling et de psychothérapie, $45,327-348$.

Fortune, S., Sinclair, J., \& Hawton, K. (2008). Adolescents' views on preventing self-harm. Social Psychiatry \& Psychiatric Epidemiology, 43, 96-104.

Fox, K. R., Franklin, J. C., Ribeiro, J. D., Kleiman, E. M., Bentley, K. H., \& Nock, M. K. (2015). Meta-analysis of risk factors for nonsuicidal self-injury. Clinical Psychology Review, 42, $156-167$. 
De Riggi, Non-Suicidal Self-Injury in Our Schools: A Review and Research-Informed Guidelines for School Mental Health Professionals, 'Canadian Journal of School Psychology' (32, 2) pp. 122-143. Copyright @ 2016 . DOI: $10.1177 / 0829573516645563$.

Gratz, K. L. (2003). Risk factors for and functions of deliberate self-harm: An empirical and conceptual review. Clinical Psychology: Science and Practice, 10, 192-205.

Guan, K., Fox, K. R., \& Prinstein, M. J. (2012). Nonsuicidal self-injury as a time-invariant predictor of adolescent suicide ideation and attempts in a diverse community sample. Journal of Consulting and Clinical Psychology, 80, 842-849.

Hamza, C. A., Stewart, S. L., \& Willoughby, T. (2012). Examining the link between nonsuicidal self-injury and suicidal behavior: A review of the literature and an integrated model. Clinical Psychology Review, 32, 482-495.

Heath, N. L., Baxter, A. L., Toste, J. R., \& McLouth, R. (2010). Adolescents' willingness to access school-based support for nonsuicidal self-injury. Canadian Journal of School Psychology, 25, 260-276.

Heath, N. L., \& Lewis, S. P. (2013). Nonsuicidal self-injury in our schools, from research to practice: Introduction to the special issue. School Psychology Forum, 7, 89-92.

Heath, N. L., \& Nixon, M. K. (2009). Assessment of nonsuicidal self-injury in youth. In M. K. Nixon \& N. L. Heath (Eds.), Self-injury in youth: The essential guide to assessment and intervention (pp. 143-170). New York, NY: Routledge.

Heath, N. L., Schaub, K. M., Holly, S., \& Nixon, M. K. (2008). Self-injury today: Review of population and clinical studies in adolescents. In M. K. Nixon \& N. L. Heath (Eds.), Selfinjury in youth: The essential guide to assessment and intervention (pp. 9-28). New York, NY: Routledge.

Heath, N. L., Toste, J. R., \& Beettam, E. L. (2006). “I am not well-equipped” high school teachers’ perceptions of self-injury. Canadian Journal of School Psychology, 21, 73-92.

Heath, N. L., Toste, J. R., Nedecheva, T., \& Charlebois, A. (2008). An examination of non- 
De Riggi, Non-Suicidal Self-Injury in Our Schools: A Review and Research-Informed Guidelines for School Mental Health Professionals, 'Canadian Journal of School Psychology' (32, 2) pp. 122-143. Copyright @ 2016 . DOI:

$10.1177 / 0829573516645563$.

suicidal self-injury among college students. Journal of Mental Health Counseling, 30,

137-156.

Heath, N. L., Toste, J. R., Sornberger, M. J., \& Wagner, C. (2011). Teachers’ perceptions of nonsuicidal self-injury in the schools. School Mental Health, 3, 35-43.

Hintikka, J., Tolumen, T., Rissanen, M. L., Honkalampi, K., Kylmä, J., \& Laukkanen, E. (2009). Mental disorders in self-cutting adolescents. Journal of Adolescent Health, 44, 464-467.

Jacobson, C. M., \& Gould, M. (2007). The epidemiology and phenomenology of non-suicidal self-injurious behavior among adolescents: A critical review of the literature. Archives of Suicide Research, 11, 129-147.

Jacobson, C. M., Muehlenkamp, J. J., Miller, A. L., \& Turner, J. B. (2008). Psychiatric impairment among adolescents engaging in different types of deliberate self-harm. Journal of Clinical Child \& Adolescent Psychology, 37, 363-375.

Jarvi, S., Jackson, B., Swenson, L., \& Crawford, H. (2013). The impact of social contagion on non-suicidal self-injury: A review of the literature. Archives of Suicide Research, 17, 119. Klonsky, E. D. (2007). The functions of deliberate self-injury: A review of the empirical evi-

dence. Clinical Psychology Review, 27, 226-239.

Klonsky, E. D. (2009). The functions of self-injury in young adults who cut themselves: Clarifying the evidence for affect-regulation. Psychiatry Research, 166, 260-268.

Klonsky, E. D., \& Glenn, C. R. (2009). Assessing the functions of non-suicidal self-injury: Psychometric properties of the Inventory of Statements About Self-Injury (ISAS). Journal of Psychopathology and Behavioral Assessment, 31, 215-219.

Klonsky, E. D., \& Lewis, S. P. (2014). Assessment of nonsuicidal self-injury. In M. K. Nock 
De Riggi, Non-Suicidal Self-Injury in Our Schools: A Review and Research-Informed Guidelines for School Mental Health Professionals, 'Canadian Journal of School Psychology' (32, 2) pp. 122-143. Copyright @ 2016 . DOI: $10.1177 / 0829573516645563$.

(Ed.), The Oxford handbook of suicide and self-injury (pp. 337-354). New York, NY: Oxford University Press.

Klonsky, E. D., May, A. M., \& Glenn, C. R. (2013). The relationship between nonsuicidal selfinjury and attempted suicide: Converging evidence from four samples. Journal of Abnormal Psychology, 122, 231-237.

Klonsky, E. D., \& Muehlenkamp, J. J. (2007). Self-injury: A research review for the practitioner. Journal of Clinical Psychology, 63, 1045-1056.

Klonsky, E. D., Muehlenkamp, J., Lewis, S. P., \& Walsh, B. (2011). Nonsuicidal self-injury. Cambridge, MA: Hogrefe.

Laye-Gindhu, A., \& Schonert-Reichl, K. A. (2005). Nonsuicidal self-harm among community adolescents: Understanding the "whats" and "whys" of self-harm. Journal of Youth and Adolescence, 34, 447-457.

Lewis, S. P., \& Arbuthnott, A. E. (2012). Searching for thinspiration: The nature of inter- net searches for pro-eating disorder websites. Cyberpsychology, Behavior, and Social Networking, 15, 200-204.

Lewis, S. P., \& Baker, T. G. (2011). The possible risks of self-injury web sites: A content analysis. Archives of Suicide Research, 15, 390-396.

Lewis, S. P., \& Heath, N. L. (2015). Nonsuicidal self-injury among youth. Journal of Pediatrics, $166,526-530$.

Lewis, S. P., Heath, N. L., Michal, N. J., \& Duggan, J. M. (2012a). Non-suicidal self-injury, youth, and the Internet: What mental health professionals need to know. Child and Adolescent Psychiatry and Mental Health, 6, Article 13.

Lewis, S. P., Heath, N. L., Sornberger, M. J., \& Arbuthnott, A. E. (2012b). Helpful or harm- ful? 
De Riggi, Non-Suicidal Self-Injury in Our Schools: A Review and Research-Informed Guidelines for School Mental Health Professionals, 'Canadian Journal of School Psychology' (32, 2) pp. 122-143. Copyright @ 2016 . DOI:

$10.1177 / 0829573516645563$.

An examination of viewers' responses to nonsuicidal self-injury videos on YouTube.

Journal of Adolescent Health, 51, 380-385.

Lewis, S. P., Heath, N. L., St. Denis, J. M., \& Noble, R. (2011). The scope of nonsuicidal selfinjury on YouTube. Pediatrics, 127, 552-557.

Lewis, S. P., \& Knoll, A. K. (2015). Do it yourself: Examination of self-injury first aid tips on YouTube. Cyberpsychology, Behavior, and Social Networking, 18, 301-304.

Lewis, S. P., Mahdy, J. C., Michal, N. J., \& Arbuthnott, A. E. (2014). Googling self-injury: The state of health information obtained through online searches for self-injury. JAMA Pediatrics, 168, 443-449.

Lewis, S. P., \& Michal, N. J. (2016). Start, stop, and continue: Preliminary insight into the appeal of self-injury e-communities. Journal of Health Psychology, 21, 250-260.

Lewis, S. P., Rosenrot, S. A., \& Messner, M. A. (2012c). Seeking validation in unlikely places: The nature of online questions about non-suicidal self-injury. Archives of Suicide Research, 16, 263-272.

Lewis, S. P., \& Seko, Y. (2016). A double-edged sword: A review of the potential benefits and risks of online non-suicidal self-injury activities. Journal of Clinical Psychology, 72, $249-262$.

Lieberman, R. A., Toste, J. R., \& Heath, N. L. (2009). Nonsuicidal self-injury in the schools: Prevention and intervention. In M. K. Nixon \& N. L. Heath (Eds.), Self-injury in youth: The essential guide to assessment and intervention (pp. 195-216). New York, NY: Taylor \& Francis.

Linehan, M. M., Comtois, K. A., Brown, M. Z., Heard, H. L., \& Wagner, A. (2006). Suicide Attempt Self-Injury Interview (SASII): Development, reliability, and validity of a scale 
De Riggi, Non-Suicidal Self-Injury in Our Schools: A Review and Research-Informed Guidelines for School Mental Health Professionals, 'Canadian Journal of School Psychology' (32, 2) pp. 122-143. Copyright @ 2016 . DOI:

$10.1177 / 0829573516645563$.

to assess suicide attempts and intentional self-injury. Psychological Assessment, 18, 303-

312. Lloyd-Richardson, E. E., Lewis, S. P., Whitlock, J. L., Rodham, K., \& Schatten, H. T. (2015).

Research with adolescents who engage in non-suicidal self-injury: Ethical considerations and challenges. Child and Adolescent Psychiatry and Mental Health, 9, Article 37.

Lundh, L. G., Karim, J., \& Quilisch, E. (2007). Deliberate self-harm in 15-year-old adolescents: A pilot study with a modified version of the Deliberate Self-Harm Inventory. Scandinavian Journal of Psychology, 48(1), 33.

Mahdy, J. C., \& Lewis, S. P. (2013). Nonsuicidal self-injury on the Internet: An overview and guide for school mental health professionals. School Psychology Forum, 7, 148-160.

McKenzie, K. C., \& Gross, J. J. (2014). Nonsuicidal self-injury: An emotion regulation perspective. Psychopathology, 47, 207-219.

Muehlenkamp, J. J. (2005). Self-injurious behavior as a separate clinical syndrome. American Journal of Orthopsychiatry, 75, 324-333.

Muehlenkamp, J. J., Brausch, A., Quigley, K., \& Whitlock, J. (2013). Interpersonal features and functions of nonsuicidal self-injury. Suicide and Life-Threatening Behavior, 43, 67-80. Muehlenkamp, J. J., Claes, L., Havertape, L., \& Plener, P. L. (2012). International prevalence of adolescent non-suicidal self-injury and deliberate self-harm. Child and Adolescent Psychiatry and Mental Health, 6, Article 10.

Muehlenkamp, J. J., \& Gutierrez, P. M. (2004). An investigation of differences between selfinjurious behavior and suicide attempts in a sample of adolescents. Suicide and LifeThreatening Behavior, 34, 12-23.

Muehlenkamp, J. J., Hoff, E. R., Licht, J. G., Azure, J. A., \& Hasenzahl, S. J. (2008). Rates of 
De Riggi, Non-Suicidal Self-Injury in Our Schools: A Review and Research-Informed Guidelines for School Mental Health Professionals, 'Canadian Journal of School Psychology' (32, 2) pp. 122-143. Copyright @ 2016 . DOI:

$10.1177 / 0829573516645563$.

non-suicidal self-injury: A cross-sectional analysis of exposure. Current Psychology, 27, 234-241.

Muehlenkamp, J. J., Walsh, B. W., \& McDade, M. (2010). Preventing non-suicidal self-injury in adolescents: The signs of self-injury program. Journal of Youth and Adolescence, 39, 306-314.

Muehlenkamp, J. J., Williams, K. L., Gutierrez, P. M., \& Claes, L. (2009). Rates of non-suicidal self-injury in high school students across five years. Archives of Suicide Research, 13, 317-329.

Nixon, M. K., Cloutier, P., \& Jansson, S. M. (2008). Nonsuicidal self-harm in youth: A population-based survey. Canadian Medical Association Journal, 178, 306-312.

Nixon, M. K., \& Heath, N. L. (2009). Self-injury in youth: The essential guide to assessment and intervention. New York, NY: Taylor \& Francis.

Nixon, M. K., Levesque, C., Preyde, M., Vanderkooy, J., \& Cloutier, P. F. (2015). The Ottawa Self-Injury Inventory: Evaluation of an assessment measure of nonsuicidal self-injury in an inpatient sample of adolescents. Child and Adolescent Psychiatry and Mental Health, 9, Article 26.

Nock, M. K. (2009). Why do people hurt themselves? New insights into the nature and functions of self-injury. Current Directions in Psychological Science, 18, 78-83.

Nock, M. K. (2010). Self-injury. Annual Review of Clinical Psychology, 6, 339-363.

Nock, M. K. (2012). Future directions for the study of suicide and self-injury. Journal of Clinical Child \& Adolescent Psychology, 41, 255-259.

Nock, M. K., \& Favazza, A. (2009). Non-suicidal self-injury: Definition and classification. In M. K. Nock (Ed.), Understanding non-suicidal self-injury: Origins, assessment, and treat- 
De Riggi, Non-Suicidal Self-Injury in Our Schools: A Review and Research-Informed Guidelines for School Mental Health Professionals, 'Canadian Journal of School Psychology' (32, 2) pp. 122-143. Copyright @ 2016 . DOI:

$10.1177 / 0829573516645563$.

ment (pp. 9-18). Washington, DC: American Psychological Association.

Nock, M. K., Holmberg, E. B., Photos, V. I., \& Michel, B. D. (2007). Self-Injurious Thoughts and Behaviors Interview: Development, reliability, and validity in an adolescent sample. Psychological Assessment, 19, 309-317.

Nock, M. K., Joiner, T. E., Gordon, K. H., Lloyd-Richardson, E., \& Prinstein, M. J. (2006). Nonsuicidal self-injury among adolescents: Diagnostic correlates and relation to suicide attempts. Psychiatry Research, 144, 65-72.

Nock, M. K., \& Mendes, W. B. (2008). Physiological arousal, distress tolerance, and social problem-solving deficits among adolescent self-injurers. Journal of Consulting and Clinical Psychology, 76, 28-38.

Nock, M. K., \& Prinstein, M. J. (2004). A functional approach to the assessment of selfmutilative behavior. Journal of Consulting and Clinical Psychology, 72, 885-890.

Nock, M. K., \& Prinstein, M. J. (2005). Contextual features and behavioral functions of selfmutilation among adolescents. Journal of Abnormal Psychology, 114, 140-146.

Nock, M. K., Prinstein, M. J., \& Sterba, S. K. (2009). Revealing the form and function of selfinjurious thoughts and behaviors: A real-time ecological assessment study among adolescents and young adults. Journal of Abnormal Psychology, 118, 816-827.

Polk, E., \& Liss, M. (2009). Exploring the motivations behind self-injury. Counselling Psychology Quarterly, 22, 233-241.

Rodham, K., Gavin, J., Lewis, S. P., St. Denis, J. M., \& Bandalli, P. (2013). An investigation of the motivations driving the online representation of self-injury: A thematic analysis. Archives of Suicide Research, 17, 173-183.

Rodham, K., \& Hawton, K. (2009). Epidemiology and phenomenology of non-suicidal self- 
De Riggi, Non-Suicidal Self-Injury in Our Schools: A Review and Research-Informed Guidelines for School Mental Health Professionals, 'Canadian Journal of School Psychology' (32, 2) pp. 122-143. Copyright @ 2016 . DOI:

$10.1177 / 0829573516645563$.

injury. In M. Nock (Ed.), Understanding non-suicidal self-injury: Origins, assessment, and treatment (pp. 37-62). Washington, DC: American Psychological Association.

Rodham, K., Hawton, K., \& Evans, E. (2004). Reasons for deliberate self-harm: Comparison of self-poisoners and self-cutters in a community sample of adolescents. Journal of the American Academy of Child \& Adolescent Psychiatry, 43, 80-87.

Rosen, P. M., \& Walsh, B. W. (1989). Patterns of contagion in self-mutilation epidemics.

American Journal of Psychiatry, 146, 656-658.

Ross, S., Heath, N. L., \& Toste, J. R. (2009). Non-suicidal self-injury and eating pathology in high school students. American Journal of Orthopsychiatry, 79, 83-92.

Rowe, S. L., French, R. S., Henderson, C., Ougrin, D., Slade, M., \& Moran, P. (2014). Helpseeking behaviour and adolescent self-harm: A systematic review. Australian \& New Zealand Journal of Psychiatry, 48, 1083-1095.

Serras, A., Saules, K. K., Cranford, J. A., \& Eisenberg, D. (2010). Self-injury, substance use, and associated risk factors in a multi-campus probability sample of college students. Psychology of Addictive Behaviors, 24, 119-128.

Sheppes, G., Suri, G., \& Gross, J. J. (2015). Emotion regulation and psychopathology. Annual Review of Clinical Psychology, 11, 379-405.

Simon, R. I., \& Hales, R. E. (Eds.). (2012). The American Psychiatric Publishing textbook of suicide assessment and management. Arlington, VA: American Psychiatric Publishing. Sornberger, M. J., Heath, N. L., Toste, J. R., \& McLouth, R. (2012). Nonsuicidal selfinjury and gender: Patterns of prevalence, methods, and locations among adolescents. Suicide and Life-Threatening Behavior, 42, 266-278.

Stewart, S. L., Baiden, P., \& Theall-Honey, L. (2014). Examining non-suicidal self-injury among 
De Riggi, Non-Suicidal Self-Injury in Our Schools: A Review and Research-Informed Guidelines for School Mental Health Professionals, 'Canadian Journal of School Psychology' (32, 2) pp. 122-143. Copyright @ 2016 . DOI: $10.1177 / 0829573516645563$.

adolescents with mental health needs, in Ontario, Canada. Archives of Suicide Research, $18,392-409$.

Swannell, S. V., Martin, G. E., Page, A., Hasking, P., \& St John, N. J. (2014). Prevalence of nonsuicidal self-injury in nonclinical samples: Systematic review, meta-analysis and meta- regression. Suicide and Life-Threatening Behavior, 44, 273-303.

Taliaferro, L. A., \& Muehlenkamp, J. J. (2015). Risk factors associated with self-injurious behavior among a national sample of undergraduate college students. Journal of American College Health, 63, 40-48.

Taliaferro, L. A., Muehlenkamp, J. J., Hetler, J., Edwall, G., Wright, C., Edwards, A., \& Borowsky, I. W. (2013). Nonsuicidal self-injury among adolescents: A training priority for primary care providers. Suicide and Life-Threatening Behavior, 43, 250-261.

Toste, J. R., \& Heath, N. L. (2010). School response to non-suicidal self-injury. The Prevention Researcher, 17(1), 14-17.

Victor, S. E., \& Klonsky, E. D. (2014a). Correlates of suicide attempts among self-injurers: A meta-analysis. Clinical Psychology Review, 34, 282-297.

Victor, S. E., \& Klonsky, E. D. (2014b). Daily emotion in non-suicidal self-injury. Journal of Clinical Psychology, 70, 364-375.

Walsh, B. W. (2012). Treating self-injury: A practical guide. New York, NY: Guilford Press. Walsh, B. W., \& Muehlenkamp, J. J. (2013). Managing nonsuicidal self-injury in schools:

Use of a structured protocol to manage the behavior and prevent social contagion. School Psychology Forum, 7, 161-171.

Walsh, B. W., \& Rosen, P. (1985). Self-mutilation and contagion: An empirical test. American 
De Riggi, Non-Suicidal Self-Injury in Our Schools: A Review and Research-Informed Guidelines for School Mental Health Professionals, 'Canadian Journal of School Psychology' (32, 2) pp. 122-143. Copyright @ 2016 . DOI:

$10.1177 / 0829573516645563$.

Journal of Psychiatry, 142, 19-120.

Web of Science. (n.d.). Retrieved January, 2015, from https://apps.webofknowledge.com/ $\underline{\mathrm{S} \text { e }}$

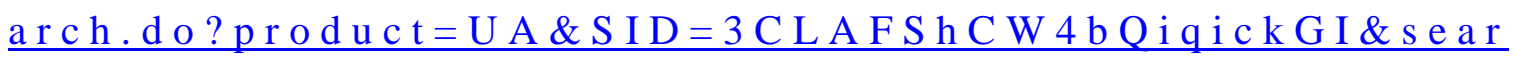
$\underline{\mathrm{ch}} \underline{\text { mode }=\text { GeneralSearch \&prID }=69064232-\mathrm{d} 55 \mathrm{f}-46 \mathrm{aa}-93 \mathrm{ba}-\mathrm{ac} 65 \mathrm{c} 4 \mathrm{~d} 42 \mathrm{f} 4 \mathrm{e}}$

White Kress, V. E., Drouhard, N., \& Costin, A. (2006). Students who self-injure: School counselor ethical and legal considerations. Professional School Counseling, 10, 203-209.

White Kress, V. E., Gibson, D. M., \& Reynolds, C. A. (2004). Adolescents who self-injure: Implications and strategies for school counselors. Professional School Counseling, 7, 195-201.

Whitlock, J., Eckenrode, J., \& Silverman, D. (2006a). Self-injurious behaviors in a college population. Pediatrics, 117, 1939-1948.

Whitlock, J., Exner-Cortens, D., \& Purington, A. (2014). Assessment of nonsuicidal self-injury: Development and initial validation of the Non-Suicidal Self-Injury-Assessment Tool (NSSI-AT). Psychological Assessment, 26, 935-946.

Whitlock, J., Muehlenkamp, J., Eckenrode, J., Purington, A., Abrams, G. B., Barreira, P., \& Kress, V. (2013). Nonsuicidal self-injury as a gateway to suicide in young adults. Journal of Adolescent Health, 52, 486-492.

Whitlock, J., Muehlenkamp, J., Purington, A., Eckenrode, J., Barreira, P., Baral Abrams, G., \& Knox, K. (2011). Nonsuicidal self-injury in a college population: General trends and sex differences. Journal of American College Health, 59, 691-698.

Whitlock, J., Powers, J. L., \& Eckenrode, J. (2006b). The virtual cutting edge: The Internet and adolescent self-injury. Developmental Psychology, 42, 407-417.

Whitlock, J., \& Rodham, K. (2013). Understanding nonsuicidal self-injury in youth. School 
De Riggi, Non-Suicidal Self-Injury in Our Schools: A Review and Research-Informed Guidelines for School Mental Health Professionals, 'Canadian Journal of School Psychology' (32, 2) pp. 122-143. Copyright @ 2016 . DOI:

$10.1177 / 0829573516645563$.

Psychology Forum, 7, 93-110.

Wilcox, H. C., Arria, A. M., Caldeira, K. M., Vincent, K. B., Pinchevsky, G. M., \& O’Grady, K. E. (2012). Longitudinal predictors of past-year non-suicidal self-injury and motives among college students. Psychological Medicine, 42, 717-726. 